\title{
Brazilian drug companies hope to benefit from foreign investment
}

Brazil's drug industry is booming — and foreign drugmakers are hoping to cash in. Ever since France's Sanofi acquired Brazil's leading generic manufacturer Medley two years ago, a who's who of multinational companies has been pouring money into the country's biopharmaceutical firms. For instance, GlaxoSmithKline, Novartis and Takeda all now have major investments in the local drug industry.

"Our clients are looking at Brazil as a key investment and growth area," says Kay Formanek, who leads the life science practice in Europe, Africa and Latin America for Accenture, a global management and consulting firm. Experts from big pharma agree. Brazil is "one of the main countries in [Merck's] emerging market strategy," says João Sanches, market access and external affairs director for the Whitehouse Station, New Jersey-based company.

The most recent major takeover comes from the world's largest biotech company. In April, Thousand Oaks, California-based Amgen bought the Brazilian pharmaceutical firm Bergamo for a cool \$215 million. The takeover comes less than a year after New York-based Pfizer, the biggest drugmaker in the world, paid $\$ 240$ million for a $40 \%$ stake in Brazil's Teuto with an option to acquire the rest of the generic drug specialist's shares beginning in 2014.
According to Ricardo Vicente, a pharmaceuticals analyst with UK-based Espicom Business Intelligence, all this foreign investment should help the country's annual drug sales grow from around $\$ 31$ billion today to close to $\$ 39$ billion by 2016 . "Foreign investment will certainly fuel pharmaceutical market growth," he says. Indeed, at the current pace of growth, Brazil could become the world's fifth largest pharmaceutical market-behind only the US, Japan, China and Germany-by 2015.

Brazil offers a suite of attractive features for multinational drug companies looking to invest. For one thing, the country's per capita gross domestic product (GDP) has nearly tripled over the past decade-from $\$ 3,696$ in 2000 to $\$ 10,710$ last year-with a large fraction of that being put toward drugs. According to Vicente, Brazil now spends approximately $9 \%$ of its GDP on health care, and about one-sixth of that goes toward pharmaceuticals.

\section{Chronic opportunities}

With a shift from infectious diseases to noncommunicable ailments, the country's epidemiological profile is also becoming increasingly attractive to big pharma. "Chronic and degenerative diseases are the leading causes of morbidity [in Brazil]," Vicente says. "Drugs to treat these diseases are expensive; therefore, the pharmaceutical market will remain attractive."

What's more, recent actions by Brazil's government are enhancing opportunities for biopharma. In December of last year, for instance, the country's national health surveillance agency, ANVISA, provided guidelines for companies wishing to bring 'biosimilar' drugs to market-something that other countries, including the US, have been struggling to accomplish. The government also recently introduced several drug-safety measures and established public-private partnerships to help roll out essential medicines, many of them sold by foreign companies.

According to Formanek, the growing investment by foreign drugmakers should rub off on locally owned companies, too. It will "create a ripple effect in terms of the requirements for clinical experts, physicians and so on," she says. For one thing, she expects to see research and development hubs popping up around the facilities being established by multinationals.

"Brazil will be codependent on multinationals for innovative medicines for the near future, because local companies lack the capacity to produce key products like vaccines," Formanek adds. But, she notes, "with investments and acquisitions, also fostered by the government, this gap will be closing in the next few years."

Mike May

\section{New framework needed to thwart Brazil's crippling bureaucracy}

RIO DE JANEIRO - Scientists around the globe often dream about vacationing in Brazil to waste some time on the beaches near Rio and São Paolo. But for researchers who regularly work in the biomedical strongholds of the country there's a far more insidious timewaster: bureaucracy.

To eliminate some of the red tape that has been blamed for stultifying research and innovation, an expert panel representing state funding agencies and science secretaries released a report on 26 August calling for a new code of conduct governing how scientific research is carried out in Brazil.

"The present context discourages scientists and hinders the scientific and technological development of the country," says Mário Neto Borges, president of the National Council of State Research Funding Foundations (CONFAP). "If approved, the new code will be a big step for Brazilian science-a revolution," adds Odenildo Sena, president of the National Council of Secretaries for Science, Technology and Innovation Issues (CONSECTI).

Currently, provisions relating to importing research equipment or grant spending, for example, are spread out across at least ten different pieces of legislation. The architects of the new report hope to bring all these measures together into one place and to lower some of the bureaucratic hurdles along the way. For instance, the 25-page proposal-coauthored by CONFAP and CONSECTI-calls for an elimination of import tariffs on research tools and reagents as well as outlines specific ways that scientists can get the lowest prices to stretch their grant money further. "The suggested code is a single, comprehensive, simple legislation specific to science," Borges says.

Miguel Nicolelis, a Brazilian-born neuroscientist who works both at the Duke
University Medical Center in Durham, North Carolina and at the Edmond and Lily Safra International Institute of Neuroscience of Natal in northeastern Brazil, hopes these measures will streamline biomedical research in his native country. "In the US, if I need to buy something for a research project, I just pick up the phone and buy it," he notes. "In Brazil, the rules are the same as for building a hydroelectric plant. The rules are not made for science."

Luiz Antonio Elias, executive secretary of the Brazilian Ministry of Science, Technology and Innovation, welcomes the new proposal. "This is an original movement in which both state and national stakeholders joined for suggesting an improvement of the legislation," he says. According to Elias, the ministry now plans to work with the scientific community to address any outstanding concerns and to codify some of the report's proposals into law.

Luisa Massarani 